\title{
Detecting Forest Cover and Ecosystem Service Change Using Integrated Approach of Remotely Sensed Derived Indices in the Central Districts of Uganda
}

\author{
A.A.Ssentongo ${ }^{1}$, D. Darkey ${ }^{1}$, and J.Mutyaba ${ }^{2}$ \\ ${ }^{1}$ Centre for Environmental Studies, Department of Geography, Geoinformatics and Meteorology, \\ University of Pretoria, Pretoria 0002, South Africa. Alternate address P.O. Box 2555 Mbale, \\ Uganda, e-mail: ausisento@gmail.com \\ ${ }^{2}$ National Forestry Authority, 10/20 Spring Road, P.O Box 70863 Bugolobi, Kampala, Uganda.
}

DOI: $\underline{\text { http://dx.doi.org/10.4314/sajg.v7i1.4 }}$

\begin{abstract}
Natural forests in Uganda have experienced both spatial and temporal modifications from different drivers which need to be monitored to assess the impacts of such changes on ecosystems and prevent related risks of reduction in ecosystem service benefits. Ground investigations may be complex because of dual ownership, whereas remote sensing techniques and GIS application enable a fast multi-temporal detection of changes in forest cover and offer a cost-effective option for inaccessible areas and their use to detect ecosystem service change. The overarching goal of this study was to use satellite measurements to study forest change and link it to ecosystem service benefit reduction (fresh water) in the study area using a representative sample of Landsat scenes, also testing whether the inclusion of ecosystem service benefits improves the classification. In this paper, an integrated approach of remotely derived indices was used together with post-classification comparison to detect forest cover and ecosystem service changes. Our contribution novelty is the ability to detect at multi-temporal scale private and central reserve forest cover decline along with ecosystem benefit reduction using remotely derived indices in the 20 year period (1986-2005). Change detection analysis showed that forest cover declined significantly in five sub-counties of Mpigi, than in Butambala by 5.99\%, disturbed forest was 3\%, farm land increased by 44\%, grassland declined by $62.5 \%$ and light vegetation increased by63.6\%. The two most affected areas also experienced fresh water reductions. For sustainable supply of ecosystem service benefits, resource managers must also involve private resource owners in the conservation effort.
\end{abstract}

Keywords: Change detection, forest cover, ecosystem service, remotely sensed derived indices, central districts of Uganda.

\section{Introduction}

Changes in natural resources as manifested in land-cover and land-use-change (LCLUC) is one of the most important components of global environmental change (Foley et al., 2005). The global concern in terms of climate change is also related to changes in forests particularly their ability to sequester atmospheric carbon, and the mitigation of climate change (FAO, 2010). Mitigation of climate change impacts on ecosystem services requires more attention and monitoring of forest cover 
changes. Forests provide crucial ecosystem services for human wellbeing among which is provisioning services such as fresh water and regulating services like water flow. The loss and degradation of natural forests is accompanied by decline in supply of many ecosystem service benefits used by riparian rural communities (Byron and Anold, 1999), in particular fresh water reduction. While global climate change has received scientific explanation, local climate change or forest cover loss with impact on ecosystem service benefits has not been given deserved attention and empirical testing (Williams et al., 2013; Coeet al., 2011; Brown et al., 2012)

LCLUC is often linked to socio-economic changes as ex-ante drivers, leading to conceptual models that describe LCLUC as a function of a country's social and economic changes (Foley et al., 2005; Lambin et al., 2003). While these conceptual models usually assume relatively a causal-effect dimension, it is less clear how LCLUC impact on ecosystem service benefit provision, and also whether the incorporation of ecosystem service benefit regime change improve the classification of Land- Use (LU) classes.

Many parts of East Africa and Uganda in particular have experienced dramatic changes in landcover and land use at a variety of spatial and temporal scales during the last 3 decades, due to both climatic variability and human activities (Kiage et al., 2007). Information on such changes is often required for planning, management, conservation and protection of natural forests and their ecosystems. Many studies on deforestation in Uganda were much concerned with forest cover decline and the rate of degradation (Namaalwa et al, 2007; Abwoli et al., 2007;FAO, 2005; NBMS, 2003; Abwoli, 2001; Kayanja and Byarugaba, 2001), but not empirically testing the link between decline in forest cover and ecosystem service benefits change. Changes that are of great interest to ecologists and resource managers are those that are linked to human activities such as deforestation and land clearing for other purposes, and their impact on ecosystem benefits.

Satellite remote sensing plays a crucial role in providing information on land cover-land use modifications on local, regional and even global scales, especially where aerial photographs on temporal scale are expensive and missing (Baumann et al., 2012; Kiage et al., 2007). It has the ability to detect and monitor fluxes in land-cover depending to its capability to adequately deal with the reference database while simultaneously accounting for temporal variability and long- term secular change (in both surface and terrestrial) as well as providing information on change rate, spatial distribution of changed types and accurate assessment. Satellite remote sensing techniques have been applied extensively for monitoring and detecting change in a variety of natural environments (Kiage et al. 2007; Wulder et al. 2006; Jin and Sader 2005). Change detection as defined by Hoffer (1978) is temporal effects as variation in spectral response involves situations where the spectral characteristics of the vegetation or other cover type in a given location change over time. It's also a process that observes the differences of an object or phenomenon at different times (Singh, 1989) thus forest cover change detection in images of a given scene acquired at different times is one of the most interesting topics in the remote sensing field. 
Landsat sensors such as TM and ETM+ provide medium resolution data of (30m) that can be used to study forest cover change and are continuously available from 1970s depending on the region, to present. For the best way to link forest cover change dynamics and local ecosystem service across a region it requires to statistically sample a subset of Landsat scenes, there by greatly reducing on the amount of data needed. The approach of sampling a subset of Landsat scenes was also used in USA as part of the North American Forest Dynamics (NAFD) project Goward et al, (2008); used by (Gibbs et al., 2010) when investigating agricultural expansion on expense of intact forests. Similarly, Achard et al, (2002) used a sample of overall 100 Landsat scenes to study the world's humid tropical forests in the TREES-2 project. The FAO Forest Resources Assessment 1990 used a stratified sample of 117 Landsat TM scenes in the tropics containing at least $10,000 \mathrm{~km}^{2}$ land surface (FAO, 1995) to assess forest cover. Stehman (2005) generally showed that focusing on a sample rather than on the entire population yields better estimates, if during the analysis of the sample the improvement of error outweighs the introduction of the sampling error. In this study we focused on a sample of Landsat footprint with high concentration of forests to analyze forest cover changes.

The study focused on capturing local forests change within the five sub-counties selected. These included kalamba, kiringente, Mpigi, Mpigi town council, and Muduma sub-counties. Whereas use of a statistical sample reduces the number of Landsat subsets necessary for the study, it does not completely eliminate the problem of getting cloud imagery. However, care was taken to use only images with relatively low cloud cover or free-cloud imagery during the time period of interest. This study provides part of scientific evidence of casual-effect of local climate change and ecosystem service change using satellite images in the two central districts of Uganda (Butambala and Mpigi), over a 20-year period using Landsat Thematic Mapper and Enhanced Thematic Mapper Plus (TM/ETM+) imagery. The land cover changes occur naturally in a progressive and gradual way, however sometimes it may be rapid and sudden due to anthropogenic activities (Butenuth et al., 2007). While the use of two images may provide the means to identify change, the use of more than two images for long- term monitoring affords the ability to identify a greater range of processes of landscape change, including rates and dynamics (Frey and Butenuth, 2009).

The overarching goal of this study is to use satellite measurements to study forest cover change and link these changes to ecosystem service benefit reduction (fresh water) in the study area using a representative sample of Landsat scenes. Since forests are water catchment areas, with removing part of it, the area cannot hold as much water creating a drier climate (Asongu and Jingwa, 2012a,b). It's still an empirical question to be tested at least at local scale. More specifically, our objectives are to:

- Quantify changes in forest areas in relation to other types of LCLUC from 1986 to 2005

- Determine temporal trends in forest cover in the study area

- Test whether the inclusion of ecosystem service benefits improves the classification of land cover. 


\section{Study Area}

The study region includes two districts with particular focus on five sub-counties that fall under the zone 4 of agro-ecological zoning by the National Biomass Study of 2003. It's a zone of moist lowland and medium altitude areas covering most of Southern and Western Uganda in the Districts of Mpigi, Masaka, Kabarole, Hoima, Kabale, Kisoro, Nebbi and Mbale (NBS, 2003). It lies between $32^{\circ} 10^{\prime}$ 0” E \& 32 25' 0" E, and 0' 8' 0" $\mathrm{N} \& 0^{\circ} 24^{\prime}$ 0” $\mathrm{N}$ Rainfall ranges from $750 \mathrm{~mm}$ to $2000 \mathrm{~mm}$, and minimum temperatures ranges $15-17.5^{\circ} \mathrm{C}$ and maximum $17.5-20^{\circ} \mathrm{C}$ (see Figure 1 below). The study area consists of all the 13 land cover classes (NBS, 1995) out of them five stratification make up the forest sector in Uganda (see table 2 below). Based on the 2004 establishment of the National Forestry Authority (NFA) the management of local forest reserves was decentralized to be administered by district forest officials, giving them responsibility for forest management activities. While NFA remained with the mandate to manage Central Forest Reserves, this however, did not stop the illegal encroachment and degradation of forests.

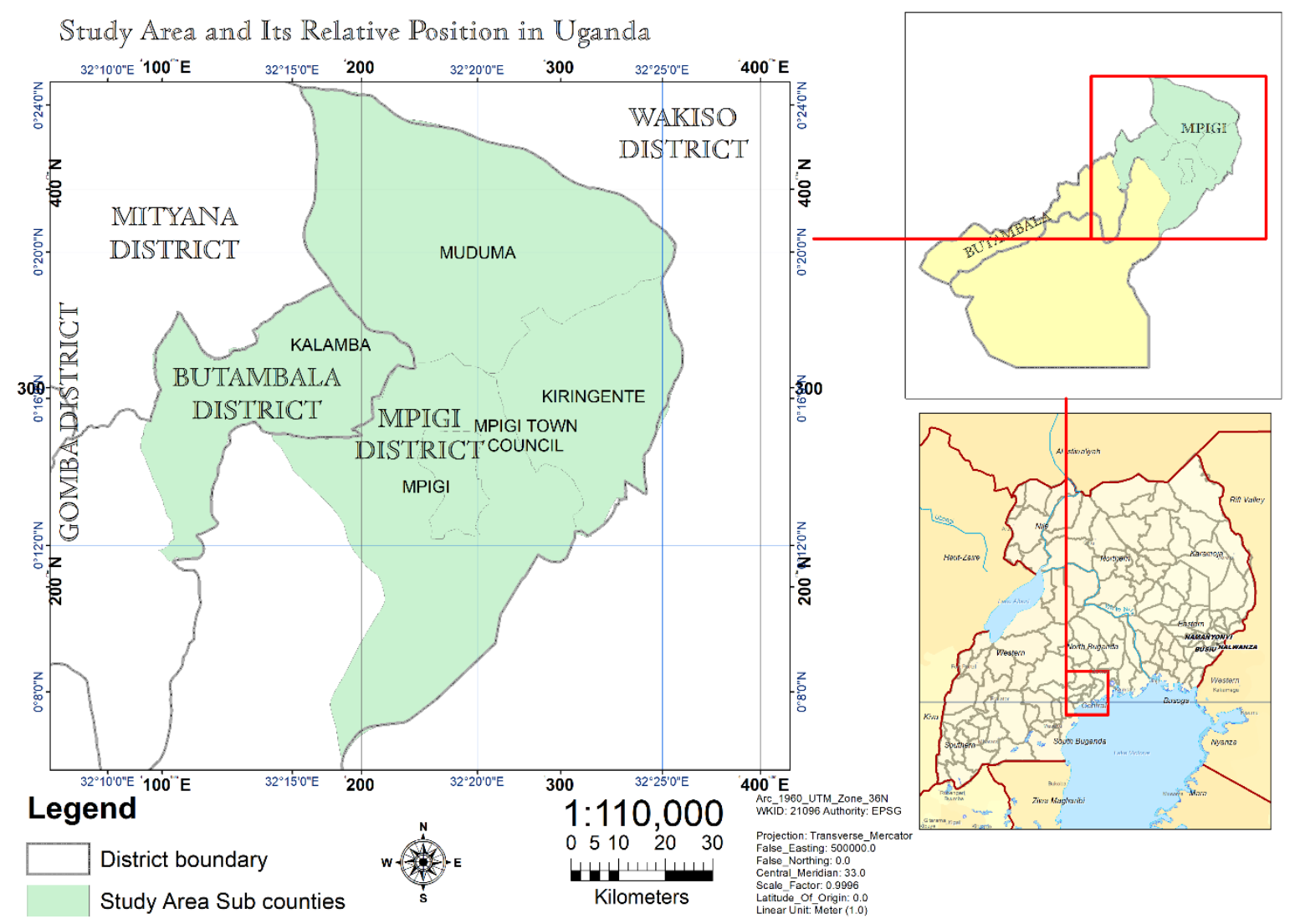

Fgure 1. Map of Study Area and its relative location in Uganda

Its biomass range 80-180 tones/ha of area covered with green during the period before 1990, with many forests both privately and publicly owned (central reserve forests). However, with the ever increasing population most of the green area has reduced, and many forests have been degraded and cleared to a level of 30-80 tones/ha in 2003 and since then decline continued. 


\section{Data and Methods}

A crucial requirement for change detection is availability of relatively cloud -free satellite image at each date. However, given the fact that the study area is within the tropics, obtaining cloud- free images is daunting task because the region tends to be cloudy almost throughout the year and therefore one has to take advantage of cloud free windows or where cloud cover is relatively very low with at least 10-20\% especially during the dry season that stretches from December up to February and June to August. Two satellite images were acquired using the Landsat 5 TM and Landsat 7 ETM+ sensors (Earth Explorer and United States Geological Survey as level 1 product in terrain - corrected quality (L1T)), thereby limiting the exogenous effects (the dates of acquisition are of January 1986, and June 2005). The effects of acquiring these images during the dry season is to reduce phonological differences and to account for the differences between pixel values influenced by some factors such as differences in atmospheric conditions, differences in sun azimuth, and differences in soil moisture. We used 5 sub-counties from the region of interest as the administrative units; that we were confident to represent the variability of forest areas and forest -cover changes in the district.

Familiarity with the area and the global positioning system (GPS) points in the field helped minimizing potential classification errors in interpretation of spectral signatures and for use in accuracy assessment. The steps involved in the methodology for this study are summarized in figure 2. Table 1 provides the general characteristics of the images used, although slight differences in spectral band width, position, and calibration exist between TM and ETM+ sensors (Teillet et al., 2001), they may not be significant enough to affect the outcome of the analyses and classification outcomes. The scenes location was based on the Landsat world wide reference system Path 172, 171 and Row 060. The two Landsat footprints were mosaicked to extract or clip the region of interest. We also acquired two land cover classification maps for 1995 and 2005 of scale 1:502,000 Universal Transverse Mercator (UTM) prepared by National Forestry Authority (NFA). These maps were used mainly for geo-referencing and accuracy assessment.

\subsection{Data- transformation and Image pre-processing}

Transformation of data using transformation techniques provides an intermediate step in the change detection process. The primary goal of data transformation is to help reveal changes in surface reflectance and results from this step are used to map change. The techniques used in this study included; pre-classification image processing, and the Normalized Difference Vegetation Index (NDVI) differencing.

For image differencing where one image (usually of the earlier date) is simply subtracted from the recent image to produce a difference image. The product of this process is to derive an image where the no change pixels are centered on the value of zero and when the image is displayed in grey scale areas with brightest tones are associated with greater change. While Nielsen et al., (1998) note that differencing non-transformed Landsat data could provide spurious results due to data noise and variable sensitivity of individual sensors, others like Kasischke et al. (2004) suggest that this 
technique may not require atmospheric correction, although atmospheric and other exogenous effects shift the mean away from zero, they do not affect the image content.

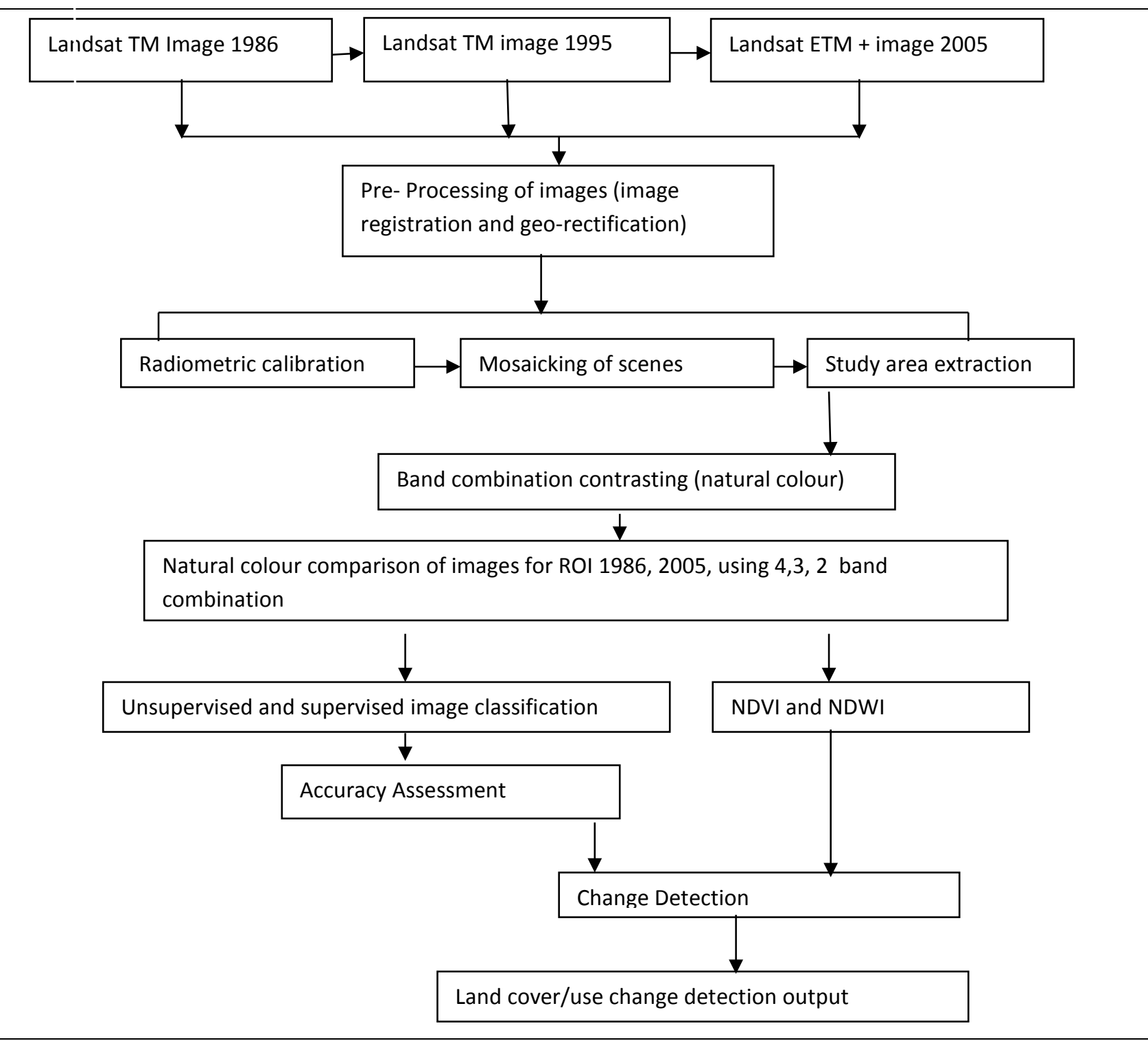

Figure 2: Summary of the change- detection procedure.

Table1. Attributes of the Landsat TM/ETM+ imagery used in the study

\begin{tabular}{|c|c|c|c|c|c|c|c|}
\hline $\begin{array}{l}\text { Acquisition } \\
\text { Date }\end{array}$ & Sensor & $\begin{array}{l}\text { Spatial } \\
\text { Resolution } \\
\text { (m) }\end{array}$ & $\begin{array}{l}\text { No. of } \\
\text { bands }\end{array}$ & Path/Row & $\begin{array}{l}\text { RMS error } \\
\text { (GCP No.) }\end{array}$ & $\begin{array}{l}\text { Sun } \\
\text { elevation }\end{array}$ & $\begin{array}{l}\text { Sun } \\
\text { azimuth }\end{array}$ \\
\hline $\begin{array}{l}10^{\text {th }} \& 17 \text { th } \\
\text { January,1986 }\end{array}$ & TM 5 & 30 & 7 & $\begin{array}{l}171 / 060 \\
172 / 060\end{array}$ & $\begin{array}{l}0.6901 \\
(16)\end{array}$ & $\begin{array}{l}47.86 \\
\& 47.80\end{array}$ & $\begin{array}{l}123.9 \& \\
121.88\end{array}$ \\
\hline $\begin{array}{l}15^{\text {th }} \& 06^{\text {th }} \quad \text { June, } \\
2005\end{array}$ & TM & 30 & 7 & $\begin{array}{l}171 / 060 \\
172 / 060\end{array}$ & Reference & $\begin{array}{l}46.29 \& \\
46.93\end{array}$ & $\begin{array}{l}106.102 \\
\& \\
102.47 \\
\end{array}$ \\
\hline
\end{tabular}

- Thermal bands were excluded in the classification and change detection process

- Images correspond to the dry seasons, December - February and June-August. 
We used NDVI image differencing to detect areas of dense vegetation which shows up very strongly in the imagery, from areas with less or no vegetation. Hence NDVI is an excellent tool for change-detection. However the study did not incorporate Kauth-Thomas Tasseled Cap Transformation (TCT) initially developed for crop-development surveys (Kauth and Thomas, 1976). It's a guided and scaled principal-components analysis (PCA) that transforms the six Landsat ETM/TM bands into three orthogonal planes or components of known characteristics (Fung 1990; Collins and Woodcock, 1994; Huang et al. 2002). Two TC components can be calculated for this transformation, the TC- Component two, Green Index (GI) is a measure of greenness obtained by comparing the NIR bands with the visible bands. The TC-component three Wetness Index (WI) in particular was used, that contrasts the sum of the visible and the Near-Infrared wave bands (NIR) bands with the longer infrared bands to determine the amount of moisture being held by the vegetation or soil (Cohen et al. 1998). It is referred to as the wetness index because of its sensitivity to soil and plant moisture (Wilson and Sader, 2002).

In pre-processing, some images had cloud contamination which were digitized and masked so as to allow proper classification. The Landsat images both TM and ETM+ were processed using ENVI 4.3 software and ArcGIS 10 for image-to-image registration. Radiometric calibration was performed before extracting the region of interest and is one of the key steps in effective mapping of vegetation change (Teillet et al. 2001; Vogelmann et al. 2004). Kasischke et al. (2004) and Olsson (1995) group radiometric pre-processing techniques for change detection into two broad categories; relative and absolute correction. The former involves attempting to match the dates of image acquisition so that such factors as sun angle and the atmosphere are the same between dates (Table 1). The effect of calibration is to set the images to appear as if they were acquired under the same illumination and atmospheric conditions. Hence to account for the differences between pixel values influenced by the factors such as differences in atmospheric conditions and soil moisture conditions, images of the same season were acquired. In absolute radiometric calibration, the original brightness values in the images are converted into surface reflectance using a number of atmospheric correction and calibration equations (Vermote et al. 1997; Lillisand and Keifer 2004). In this study we used the relative radiometric calibration.

\subsection{Training and image Classification}

The task of classifying Landsat scenes from tropics necessitates use of a training strategy that could minimize classification errors. Due to the problem of similar spectral signatures for different land cover types or different spectral signatures for the same land cover we divided each image clipped into 20 sub regions where in each region six classes are delineated. For each class we used 20 polygons as training data. On the basis of National Biomass study (1995) which had classified land cover into 13 strata, we re-categorized into six land cover classes. We based our decision for each class on the visual interpretation of the Landsat imagery and high resolution Quickbird imagery from Google Earth ${ }^{\mathrm{TM}}$. The Quickbird images were only used for the confirmation and validation purposes as they can be accessed backwards and they help in the interpretation of Landsat signatures. 
This proved useful in differentiating between farmland which had trees and grassland. The trees in farmland were interpreted as biomass stock after ground- truthing and recording of GPS points. For consistency requirement of our training data we stuck to the broader definition of forest (NBS, 1995) and non exclusion of privately owned forests. However, exclusion of succession forests were not easily delineated hence a limitation. At the pre-classification, we used the Iterative Self Organizing Data Analysis technique (ISO-DATA) unsupervised classification algorithm to obtain a summary of the spectral differences captured by the satellite images as well as to form the basis for pixel based classification in the study area and to determine the six classes. Using 20 regions of interest and selecting 20 polygons for each class, a Maximum likelihood classification algorithm in ENVI Classic software was applied since all classes could be captured to classify the composite images into the six classes.

\subsubsection{Change detection techniques}

In most studies of change detection involving the use of satellite imagery for monitoring environmental change or land cover/use changes, imagery for one date is compared with another image from different date. Different methods have been developed for analyzing images as end-points (Hobbs 1990; Coppin and Bauer 1994; Kasischke et al. 2004; Yang and Liu 2005). Some methods are more general in their applicability and others are specific in approach depending on what the researcher is investigating. The most common broad steps identified by Kasischke et al. (2004) in change detection are three; (1) radiometric preprocessing, (2) data transformation, and (3) mapping change. However not all steps are necessary for change detection studies but the relative importance is dependent on method to be used for change detection.

Image classification is used in many ways to monitor landscape changes (Muttitanon and Tripath 2005; Yang and Liu 2005). We displayed the images using false- colour composites by assigning the red, green, and blue colours to bands 4, 3 and 2 respectively. We used classification functions in ArcGIS and ENVI 4.3 to perform supervised (pixel based) classification, and maximum likelihood algorithm to amalgamate land use classes. Six classes were delineated on the basis of unsupervised classification (ISODATA) information, or inspection of images, ground truthing, translation, and familiarity with the study area. These classes were forest, farmland, grassland, cleared area, water, and bare soil which were amalgamated from the 13 NBS classes/stratification. Table 2 provides a descriptive summary of the land-cover/use classes. The classification and determination of the landcover classes were done independently for each image (figure 2). The reference data used included two land cover stratification maps 1:502,000 for the region of interest, and ground truthing involving the collection of global positioning system (GPS) points which also were the locations of springs. 
Table 2: A summarized land-cover/use stratification used in the classification of satellitederived land cover

\begin{tabular}{lcc}
\hline Land cover & NBS Codes & Description \\
\hline Forest & $1-5$ & $\begin{array}{c}\text { Plantations and woodlots (deciduous/broad leaved and coniferous } \\
\text { trees), Tropical high forests (normally stocked, depleted and } \\
\text { encroached) as well as woodland-trees and shrubs of average height } \\
\text { greater than 4 meters }\end{array}$ \\
\hline Farmland & $7 \& 8$ & $\begin{array}{r}\text { Subsistence and mixed farmlands dominated by smallholdings in use } \\
\text { or recently used with/without trees, uniform commercial farmland- } \\
\text { mono-cropped, non-seasonal farmland usually without any trees. } \\
\text { Grassland-rangelands, pastureland, open savannah, wetlands with } \\
\text { papyrus \& other sedges. } \\
\text { Bush land, thickets scrub of average height less than } 4 \text { meters. }\end{array}$ \\
\hline Light Vegetation & 6 & $\begin{array}{c}\text { Built-up area in urban or rural, and impediments (bare rocks \& soils) } \\
\text { Bare soil }\end{array}$ \\
Water & $11 \& 13$ & Open water - lakes, rivers and ponds \\
\hline
\end{tabular}

Multi-temporal remote sensing data were explored using Normalized Difference Vegetation Index (NDVI) and Normalized Difference Water Index (NDWI) analyses. The NVDI is sensitive to vegetation health and NDWI is sensitive to changes in vegetation canopy water content. The two were computed using the following equations;

$$
\begin{aligned}
& \text { NDVI }=[\text { NIR-RED }] /[\text { NIR+RED }] \\
& \text { NDWI }=[\text { NIR-MIR }] /[\text { NIR+MIR }]
\end{aligned}
$$

Where NIR= Near-Infrared (band 4), RED= red band (band 3), MIR= mid-infrared (band 5). Both indices have values ranging from -1 to 1 . The common range for green vegetation is 0.1 to 0.4 . Healthy vegetation absorbs most of the visible light that strikes on it and reflects a large portion of the near-infrared light. Values above 0.6 indicate dense vegetation and values below 0 indicate no vegetation. Bare grounds have values of $0-0.1$, grasslands have values of $0.2-0.3$, while negative values indicate water and ice surfaces.

\subsection{Analysis of forest-cover change}

To understand how forest cover changed over time in the region of interest, we reclassified the two images into forest and non-forest classes and calculated changes in forest area over the period. Forest cover changes at the district level and sub-county level are calculated using relative net change (RNC), Baumann et al. (2012) as:

$$
\mathrm{RNC}=\left(\mathrm{FC}_{1986} / \mathrm{FC}_{2005}-1\right) * 100
$$

With FC is forest cover in $\mathrm{km}^{2}$ of the described time period at district or sub-county level. We also calculated annual disturbance rates (DR) for the period as:

$$
\mathrm{DR}_{\mathrm{j}}=\left(\mathrm{D}_{\mathrm{j}} / \mathrm{FCB}_{\mathrm{j}}\right) * 100 / \mathrm{a}
$$

Where $\mathrm{D}$ is the overall area of the disturbed/degraded forest during the analyzed time period $\mathrm{j}$, FCB is the forest cover at the beginning of the same time period, and (a) is the number of years 
between acquisitions. To do this we concentrated only on areas within forest that had pixels with mixed classes, digitized them and computed area in $\mathrm{km}^{2}$ to determine disturbed area. The simplest way was to get pixels that changed from forest to other classes mainly grassland, farmland, cleared area and bare soil to constitute forest disturbed area.

\subsection{Accuracy Assessment}

Following image classification, we performed an accuracy assessment in two steps. In the first step, we assessed the accuracies for each classification individually. To do this we used the two land cover stratification maps obtained from National Forestry Authority for 1995 and 2005 to create a validation sample of polygons. This was done by using land cover class on the NFA maps to create 10 polygons for each class on the 1986 and 2005 images so as to generate a validation sample as a reference image. We then assessed the accuracy of the classification, calculated the error matrix, and derived overall accuracy, user's and producer's accuracy, and the Kappa statistic (Congalton, 1991; Congalton and Green, 1999; Foody, 2002). Image classification was carried out using all ground truth points of our sample, thereby rendering the accuracy measures conservative estimates.

In the second step we assessed the accuracy for a subset of our change maps. To do this, we used the ground truth GPS points that were recorded for springs that reduced in flow or dried completely to create a layer in ArcMap (ArcGIS 10) as ancillary data. We overlayed the two maps and used visual interpretation of how the GPS points correspond or coincide to a given class. Finally, we compared our classification for the year 1986 and 2005 with the resultant class-springs map to derive a measure of agreement and interpretation of correct class with support from ground information and explanation of local people. In addition we combine GPS of springs layer with a reclassified NDWI map with 3 categories of values $(-0.46 \&-0.12)$ to represent deforested area, $(-0.12 \& 0.04)$ to represent degraded area, and $(0.13 \& 0.4)$ to represent forested /vegetated area. The aim was to locate springs that dried up in which category of NDWI they fall.

\section{Results}

Our classification revealed that there was a persistent pattern of change from one class to another. Forest area changed substantially in our study region from $1,530,747 \mathrm{Km}^{2}$ to $1,444,122 \mathrm{Km}^{2}$ (table 3) corresponding to a decrease of $\left(813375 \mathrm{Km}^{2}\right)$ between 1986 and 2005 . Whereas grassland showed a remarkable decrease in $\mathrm{km}^{2}$, there was a corresponding increase in farmland. The explanation for this is that, there was a unidirectional change in the three classes. Land cover/use changed from forest to grassland and then to farmland.

Comparison of land cover/use classification maps for 1986 and 2005 was the basis for the change detection output (see figure 3) obtained from the classified images. There were significant changes in land cover/use involving the five classes. With forest and grassland showing a significant decrease while farmland, light vegetation and bare soil showing a remarkable increase. However, it could not be detected by this study how cleared farmland for cultivation was separate from bare soil. 
Our classification yielded accurate land cover/use maps for the two images. The results of 1986 image had over all classification accuracy of $78.8 \%$ with Kappa statistics of 0.716 . The results generally suggest that a good agreement exists between classification and the actual land cover types with minor misclassification occurring across all categories. For instance, although the producer's accuracy for forest was $91.29 \%$, the user's accuracy is slightly lower $86.47 \%$. The higher percentages of producer's accuracy for some classes imply that to certain degree they were correctly identified, while lower percentages of user's accuracy implied that the actual class was misclassified due to salt and pepper found in satellite images that could not be accurately eliminated.

For the 2005 image, land cover/use classification had a slight improvement. It had an overall classification accuracy of $82 \%$ and a Kappa coefficient of 0.77 . In this classification, the reference data and the classified groups were largely in agreement probably because of the use of improved spatial accuracy and due to use of GPS for land classes and springs location, as well as using the 1990 and 2005 land cover classes of National Forestry Authority maps. The best classes in the change maps were forest, grassland and farmland in the sense that there is a persistent conversion from forest to grassland and then farmland.

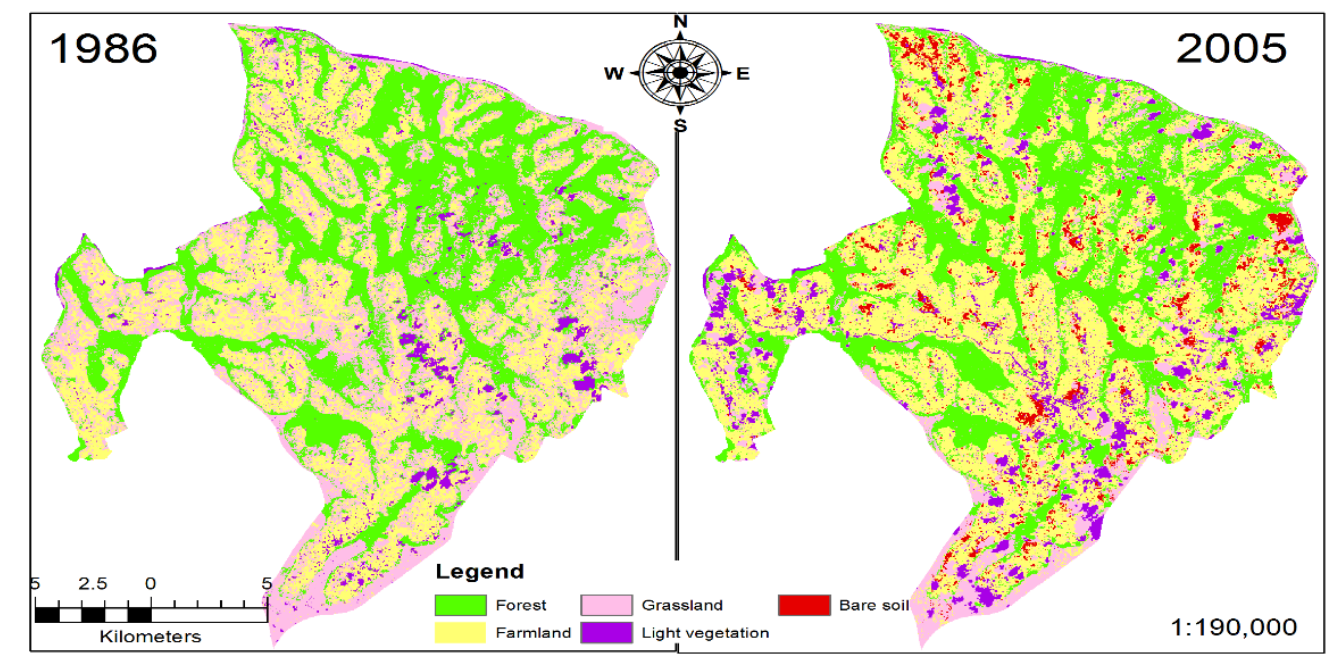

Figure 3: Land cover classes generated from supervised classification of the 1986 TM and 2005 TM images

Table 3: Results of change detection in land cover/use Classes

\begin{tabular}{llll}
\hline Land cover type & $\mathbf{1 9 8 6}\left(\mathbf{k m}^{\mathbf{2}}\right)$ & $\mathbf{2 0 0 5}\left(\mathbf{k m}^{\mathbf{2}}\right)$ & Change $\left.\mathbf{( k m}^{\mathbf{2}}\right)$ \\
\hline Forest & $1,530,747$ & $1,444,122$ & $-813,375$ \\
Farmland & $1,362,204$ & $1,962,801$ & 600,597 \\
Grassland & $1,516,671$ & 664,605 & $-947,934$ \\
Light Vegetation & 234,648 & 383,832 & 149,184 \\
Bare soil & 80,171 & 189,081 & 197.91 \\
\hline
\end{tabular}


Computation of relative net change (RNC) of forest cover throughout the entire period revealed that there was a relative net decrease in forest cover of $-5.99 \%$ between 1986 and 2005 . On the basis of post classification comparison and change detection statistics, we calculated forest disturbance rate. During the observed period, over all disturbances rate was found to be $2.929 \%$ (3\%). We used the area originally under forest that changed to other classes during the study period (mainly to farmland, grassland and light vegetation). However, the disturbed area was disaggregated into areas degraded per forest reserve resulting into within reserve variation. The highest reserve degradation occurred in Nawandigi (3.671\%), followed by Lwamunda (3.584\%) central forest reserves.

Results of NDVI analysis provide evidence for land cover change that indicate deforestation and land degradation in five sub-counties of Mpigi district. The major changes in NVDI corresponded to areas that had lost forest cover (figure 4), considering that the primary objective of this study was to investigate changes related to forest cover and land degradation. Lower values indicate an increase in the loss of vegetation between 1986 and 2005. While values below zero indicate no vegetation. Whereas NDVI values between 1986 and 2005 show increase in vegetation in some areas, over all there was loss of vegetation as shown by the larger negative values in 2005 (from -0.0128 to -0.0639).

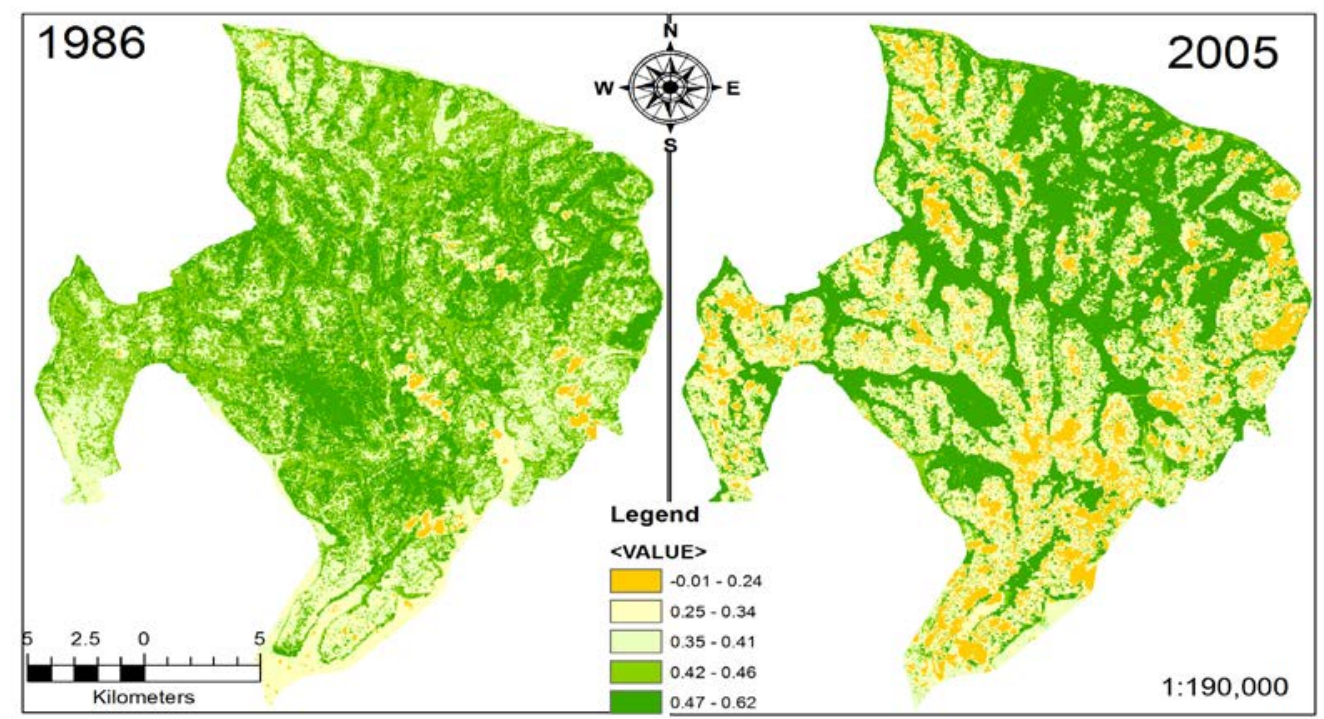

Figure 4: NDVI values for 1986 and 2005

Although forests are biodiversity and genetic resource seen as key to poverty alleviation (Food and Agriculture Organization, 2003), they are an important natural resource that provides both material goods and environmental services or ecosystem services such as water flow regulation and provision(MA,2005, IPCC draft report 2013). Deforestation is a proxy for land degradation which also implies alteration in the provision of basic ecosystem service benefits such as water.

When changes in NDVI values are combined with results of changes in NDWI values, it improves the spatial interpretation of forest cover loss. NDWI values changed in the same direction as that of NDVI such that lower values stretched from -0.301 to -0.464 indicating reduction in water content of vegetation canopy and a proxy for reduced soil moisture (figure 5). We found strong agreement 
between NDVI and NDWI values in supporting field survey findings that areas with low NDVI values corresponded to low NDWI values (figure 6) where the drying of springs/reduction in water flow was recorded (field survey). This result augment findings of Sandstrom (1995) such that forest enhance infiltration capacity and wetness of soils, which coupled with a higher water table under forests, increase the ability of forested catchment to support dry season flow of springs. Thus deforestation has a twin effect of increased overland flow and decreased infiltration in areas previously under forest cover leading to decrease in ground water recharge and dry season discharge.

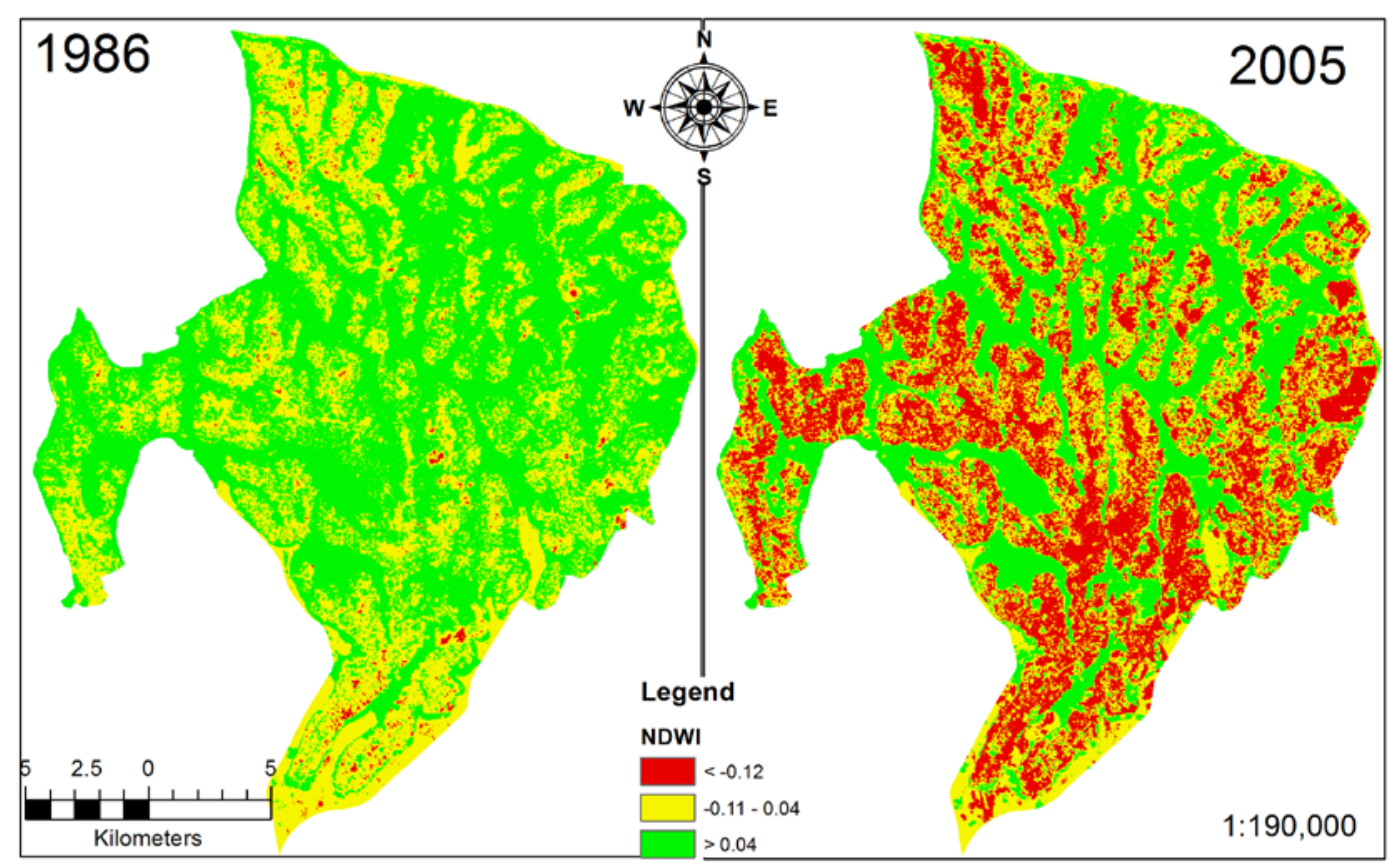

Figure 5: NDWI values for 1986 and 2005

Results of NDWI indicate whether the vegetation canopy or soil moisture had enough water content and this proxy the water (an ecosystem benefit) availability in the soil. When we laid the water spring layer with GPS locations of springs that dried up on the NDWI map it corresponded to areas that were deforested such that lower values of NDWI were corresponding well to spring locations (see figure 6 below). This robust result confirmed the field work findings that areas which were most affected by deforestation also showed reductions in water availability, indicating that deforestation in this part of Uganda in one way explain a causal-effect relationship for why springs dried hence supporting the theory of trees and resident time of water. Implying that with forest cover loss it goes with goes with an ecosystem loss or reduction such as fresh water. 


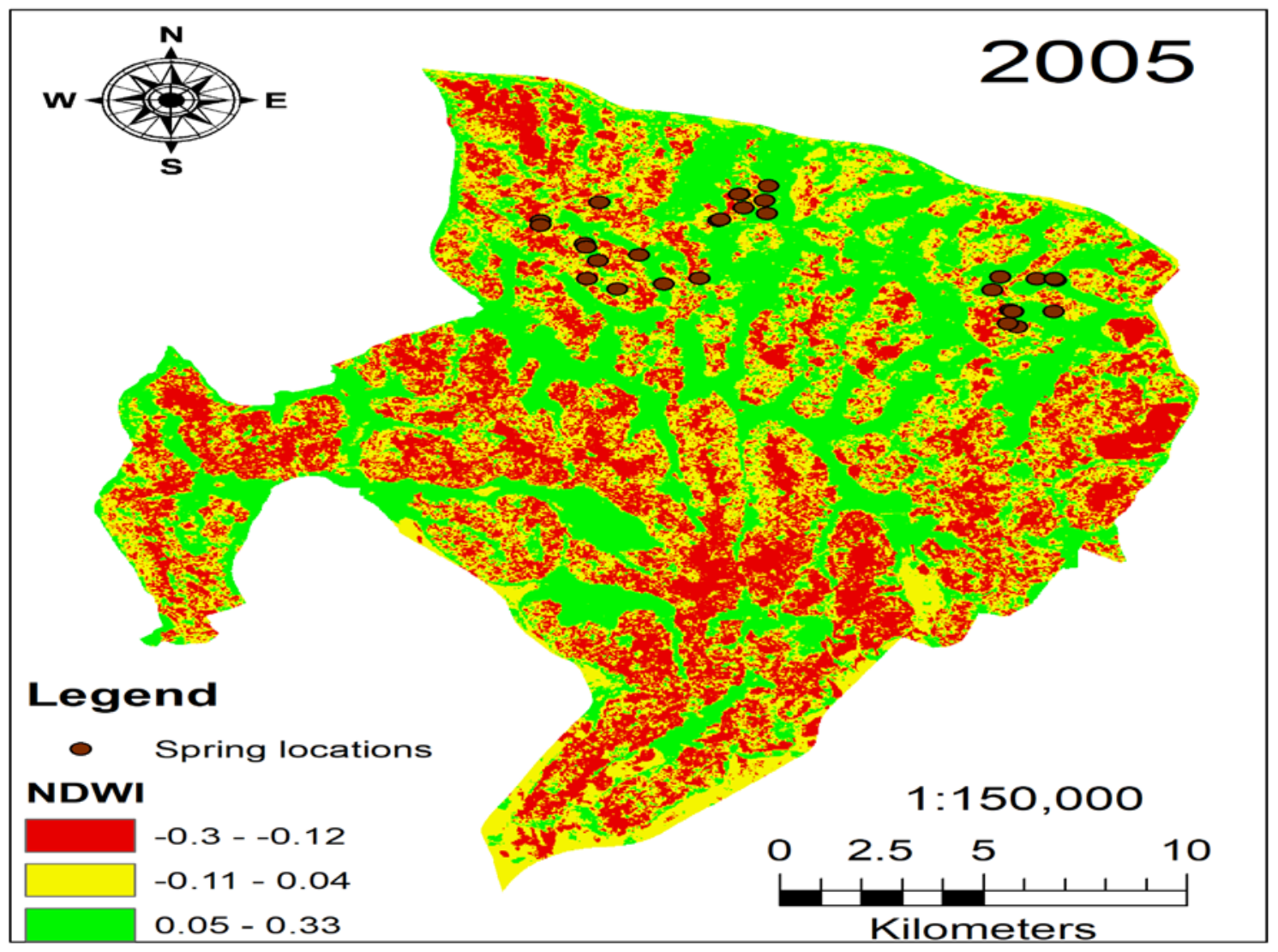

Figure 6: NDWI values and Springs Locations

\section{Discussion}

Land use changes in particular forest cover decline have been reported for both central forest reserves and privately owned forests (NFA, 2005). Using a representative subset of forest reserves within the administrative boundary of five sub-counties in Mpigi and Butambala districts, we analyzed changes in forest cover over a period of twenty years. Across the sampled sub-counties forest cover decreased during the period by $53.1 \%$. The trend analysis revealed that there was a tradeoff in land cover/use classes. The area under forest cover changed from thick forest to grassland then to farmland. The steady transformation from thick to degraded areas and then to grassland, and farmland was also reported by National Forestry Authority (2005). Field visits suggest that even more areas of forest land is continuously being encroached and turned into farmland.

Most of the deforested land in the study area is used for maize production which is a seasonal crop and can allow farmers to get crop income within a short time. Statistical data for maize production at district level shows a remarkable increase in maize production (statistical Abstract 2000-2012). We found substantial changes in the five land cover classes in the study region with forest and grassland showing significant decline (53.1\% and 62.5\%) respectively. Other classes like farmland, light vegetation and bare soil showed remarkable increase. The positive change for the three classes is attributable to shifts and trade off between these classes and partly because of spectral signatures for 
the same classes that could not differentiate tilled area from farmland for cultivation as separate from bare soil. The other explanation for these changes is the socio-economic conditions such as the upsurge in population size and the biting poverty hence the need to get quick income through seasonal crops. When the yield declines, more effort is expended to clear forest land to get fertile soil for cultivation.

The disturbance rate as recorded 3\% may be under estimation given that the commission errors for some classes in the change map are relatively high. Our results in this respect suggest different rate and patterns of change compared to official statistics. The divergence is due to different types of assessments. More specifically, while in our study we mapped forest cover and land use using remote sensing, assessed change rates using post-classification comparison, change detection statistics and summarized them under disturbance rates, the official statistics used ground truthing and spectral signatures obtained from field survey. Our analysis of relative net forest change was based on post classification comparison.

Results of NDVI analysis provide evidence for land cover /use change. The major changes in NDVI correspond to areas that had lost forest cover and those that were degraded substantially in five sub-counties of Mpigi and Butambala districts. Our analysis of change in NDVI values especially the lower values often points to change in vegetation. Between 1986 and 2005 lower values of NDVI stretched from -0.0128 to -0.0639 , on average the decline in vegetation is -0.00526 .

Similarly, our analysis of NDWI support the change in NDVI, where by lower values of NDWI indicate reduction in water content of vegetation canopy implying less water content in the soil. We reclassified NDWI values into three classes to represent deforested area (-0.46 to -0.12$)$, degraded area (-0.12 to 0.13 ) and forested/ vegetated area (0.03 to 0.4$)$. The first class of deforested area, NDWI values were corresponding to lower NDVI. This combination of NDVI and NDWI improved the spatial interpretation of forest/vegetation loss. We finally overlayed the springs layer with locations of springs / water points that dried during the study period as a result of deforestation on the NDWI map, so as to determine which category of NDWI does spring location fall. Results showed that areas with low NDWI corresponded to the location of springs that dried or reduced in flow giving strong evidence that forest cover loss affect ecosystem services negatively implying accuracy in classification of land cover during the period.

This approach showed robust results of how remote sensing can be used to monitor forest ecosystem service changes. Our approach of combining NDWI and the GPS of springs location made it possible to perform a time trend analysis of how remotely sensed derived indices are powerful in detecting ecosystem service changes.

Methodologically, our approach showed that analyzing a random sample of Landsat images across a small area is powerful in highlighting local forest ecosystem service change, and the impact on local climate change. The approach is thus well suited to situations, where the main goal is to analyze and highlight spatial-temporal variability of forest area and small area ecosystem service change. Finally our approach of using spectral indices or remotely sensed derived indices over long time, together 
with GPS locations of identified ecosystem service benefits can be useful in analyzing ecological regime or ecosystem service shifts/changes. The major output of this study is the merging of NDWI, NDVI, forest change detection and GPS for local springs which dried to characterize ecosystem service change.

\section{Conclusion}

In this paper we characterised forest cover changes and effect in ecosystem changes over a period 1986 and 2005. We used Landsat TM and $\mathrm{ETM}^{+}$to delineate land cover change and forest ecosystem change in five sub-counties of Mpigi and Butambala districts in central Uganda. Our analysis of combined NDVI and NDWI revealed that using remotely sensed derived indices are powerful in monitoring ecosystem services change. A combination of different methodologies comprised of NDVI differencing, post classification comparison and NDWI analysis effectively delineated land cover/use change and land degradation. Change detection analysis showed that forest cover declined between 1986 and 2005. Deforestation and subsequent land degradation coupled with the high evapotranspiration lead to reduction in springs flow. Our main contribution of this study is the use of remotely sensed derived indices to detect and monitor forest ecosystem service change in combination with post-classification comparison.

\section{Acknowledgements}

We gratefully acknowledge the support and permission granted to the main author by National Forestry Authority of Uganda for accessing forest reserves. Special thanks go Kibira Sula for assistance during ground data field work and image analysis.

\section{References}

Achard, F, Eva, H. D. Stibig, H. J., Mayaux, P., Gallego, J., Richards, T, et al (2002). Determination of deforestation rates of the world's humid tropical forests, science, 297, 999-1002.

Baumann M, Ozdogan, M, Kuemmerle, T, Wendland, K. J, Esipova, E, \&Radeloff, V. C. (2012). Using the Landsat record to detect forest-cover changes during and after the collapse of the Soviet Union in the temperate zone of European Russia. Remote Sensing of Environment, 124, 174-184.

Brown A. E, Western A W, McMahon T A et al.2012. Impact of forest cover changes on annual streamflow and flow duration curves. J Hydrol, 483: 39-50

Coe M T, Latrubesse, M . E, Ferreira M. E and Amsler M. L. 2011. The effects of deforestation and climate variability on the stream flow of the Araguaia River, Brazil. Biogeo chemistry, vol.105, No. 1/3:119-131.

Cohen, W. B., Fiorella, M., Gray, J., Helmer, E., \& Anderson, K., (1998). An efficient and accurate method for mapping forest cleatcuts in the Pacific Northwest using Landsat imagery. Photogrammetric Engineering and Remote Sensing, 64, 293-300.

Congalton, R. G. (1991). A review of assessing the accuracy of classifications of remotely sensed data.Remote Sensing of Environment, 37, 35-46. 
Congalton, R. G., \& Green, K. (1999).Assessing the accuracy of remotely sensed data: Principles and Practices. Boca raton FL, USA: CRC/ Lewis press.

Coppin, P.R., \& Bauer, M.E. (1994).Processing of multitemporal Landsat TM imagery to optimize extraction of forest cover features.IEEE Transactions on Geoscience and Remote Sensing, 32, 918-927.

FAO (2010). Global forest resource assessment 2010. In Food and Agriculture Organization of the United Nations (Ed.).

Foley, J. A., Defries, R., Asner, G. P., Barford, C.,Bonan, G., Carpenter, S. R. et al. (2005). Global consequences of land use, Science, 309, 570-574.

Foody, G. M. (2002).Status of land cover classification accuracy assessment. Remote Sensing of Environment, 80, 185-201.

Fung, T. (1990). An assessment of TM imagery for land-cover change detection. IEEE Transactions on Geoscience and Remote Sensing, 28, 681-684.

Gibbs, H. K., Ruesch, A.S.,Achard, F., Clayton, M. K., Holmgren, P., Ramankutty, N., et al. (2010). Tropical forests were the primary sources of new agricultural land in the 1980s and 1990s. Proceedings of the National Academy of Sciences, 107, 16732-16737.

Goward, S. N., Masek, J. G., Cohen, W. B., Moisen, G. G., Collatz, G.J., Healey, S., et al. (2008). Forest disturbance and North American Carbon flux. Earth Observing System Transactions, 89, 105-116.

Huang, C., Wylie, B., Homer, C., Yang, L. \& Zylstra, G. (2002). Derivation of a Tasseled cap transformation based on Landsat 7 at-satellite reflectance. International Journal of Remote Sensing, 23, 1741-1748.

Hobbs, R. J. (1990). Remote sensing of spatial and temporal dynamics of vegetation. In Remote sensing of Biosphere Functioning, edited by R.J. Hobbs \& H.A. Mooney (New York: Springer Verlag), 203-219.

Jin, S \& Sader, S. A. (2005). Comparison of time series tasseled cap wetness and the normalized difference moisture index in detecting forest disturbances. Remote Sensing of Environment, 94, 364-372.

Kasischke, E.S., Goetz, S., Hansen, M. C., Ustin, S. L.,Ozdogan, M., Woodcock, C. E. \& Rogan, J. (2004). Temperate and boreal forests. In Remote Sensing for Natural Resource Management and Environmental Monitoring: Manual of Remote Sensing, Vol. 4. $3^{\text {rd }}$ ed. S. L. Ustin (Ed.), (Hoboken, New Jersey: John Wiley and Sons, Inc.), 147-238.

Kauth, R. J. \& Thomas, G. S. (1976). The tasseled cap- a graphic description of the spectral-temporal development of agricultural crops seen in Landsat. In Proceedings: $2^{\text {nd }}$ International Symposium on Machine Processing of Remotely Sensed Data, 41-51 (West Lafayette, IN: LARS, Purdue University).

Kayanja, F.I.B. \&Byarugaba, D. (2001).Disappearing Forests of Uganda: The Way Forward.Current science, Vol. 81, No.8, 936-947.

Kiage, L. M., Liu, K. B., Walker, N. D., Lam, N. \& Huh, O. K. (2007). Recent land -cover/use change associated with land degradation in the Lake Baringo catchment, Kenya, East Africa: evidence from Landsat TM and ETM+. International Journal of Remote Sensing, 28, 4285-4309.

Lambin, E. F., Geist, H. J. \& Lepers, E. (2003). Dynamics of land-use and land -cover change in tropical regions. Annual Review of Environment and Resources, 28, 205-241.

Lillisand, T. M \&Keifer, R.W. (2004). Remote Sensing and Image Interpretation (New York: Wiley).

Millenium Ecosystem Assessment, 2005a. “Ecosystems and Human well-being: Synthesis”. Washington, D.C. Island Press. 
Muttitanon, W. \&Tripathi, N. K. (2005). Land use/land cover changes in the coastal zone of Ban Don Bay, Thailand using Landsat 5TM data. International Journal of Remote Sensing, 26, 2311-2333.

Namaalwa, J. (2007). A dynamic bio - economic model for analyzing deforestation and degradation: An application to Woodlands in Uganda. Elsevier Ltd, Forest Policy and Economics, 9. 479 - 495.

Olsson, H. (1995). Reflectance calibration of Thematic Mapper data for forest change detection. International Journal of Remote Sensing, 16, 81-96.

Price, K., Guo, X. \& Stiles, J. M. (2002). Optimal Landsat TM band combinations and vegetation indices for discrimination of six grassland types in eastern Kansas. International Journal of Remote sensing, 23, 5031-5042.

Stehman, S. V. (2005). Comparing estimators of gross change derived from complete coverage mapping versus statistical sampling of remotely sensed data. Remote Sensing of Environment, 96, 466-474.

Teillet, P. M., Barker, J. L., Markham, B. L., Irish, R.R., Fedosejevs, G. \& Storey, J.C. (2001). Radiometric cross-calibration of Landsat-7 ETM+ and landsat-5 TM sensors based on tandem data sets. Remote Sensing of Environment, 78, 39-54.

Wilson, E. H. \&Sader, S. A. (2002). Detection of forest harvest type using multiple dates of Landsat TM imagery. Remote Sensing of Environment, 80, 385-396.

Wulder, M. A., White, J. C., Bentz, B. j. \& Ebata, T. (2006). Augmenting the existing survey hierarchy for mountain pine beetle red-attack damage with satellite remotely sensed data. The forestry Chronicle, 82, 187-2002.

Yang, X. \& Liu, Z. (2005). Using satellite imagery and GIS for land -use and land- cover change mapping in an estuarine watershed. International Journal of Remote Sensing, 26, 5275-5296. 